\title{
ENGAGED EPISTEMIC AGENTS
}

FERNANDO BRONCANO

Universidad Carlos III de Madrid

Facultad de Humanidades, Comunicación y Documentación fernando.broncano@uc3m.es

\author{
JESÚS VEGA \\ Universidad Autónoma de Madrid \\ Facultad de Filosofía y Letras \\ jesus.vega@uam.es
}

SUMMARY: Our aim in this paper is to throw some light on the kind of normativity characteristic of human knowledge. We describe the epistemic normative domain as that field of human agency defined by knowledge understood as an achievement. The normativity of knowledge rests on the contribution of the epistemic agent to the fulfillment of certain tasks. Such contribution is epistemically significant when the agent becomes engaged in the obtaining of success. Finally, we identify some features associated with full epistemic agency (conditions of cognitive integration and epistemic autonomy) and elucidate what we mean by engagement by appealing to the idea of adopting an epistemic perspective.

KEY WORDS: epistemic normativity, normative domains, autonomy, engagement, epistemic perspective

RESUMEN: En este artículo pretendemos arrojar luz sobre la normatividad propia del conocimiento humano. Describimos el dominio normativo epistémico como un campo de agencia humana que está definido por el conocimiento entendido como logro. La normatividad del conocimiento se apoya en la contribución del agente epistémico a la consecución de ciertas tareas. Tal contribución es epistémicamente significativa cuando el agente llega a participar en la consecución del éxito. Por último identificamos algunos rasgos asociados con la agencia epistémica completa (condiciones de integración cognitiva y autonomía epistémica), y aclaramos lo que queremos decir con implicación apelando a la idea de adoptar una perspectiva epistémica.

PALABRAS CLAVE: normatividad epistémica, dominios normativos, autonomía, implicación, perspectiva epistémica

In this paper, we address the problem of epistemic normativity. Our aim is to throw some light on the kind of normativity characteristic of human knowledge. To do so we describe what we call normative domains. We carry on our views in the framework of virtue epistemology. In general, such approaches pertain to the so-called anti-luck epistemologies, that is, epistemologies that consider that knowledge is something not merely attained by luck. Thus certain expressions and vocabulary used in this paper may sound too idiosyncratic and 
dependent on these views. We contend, however, that our proposal of grounding normativity in commitments to accept regulation by constitutive properties of normative domains is largely independent of virtue epistemology and intends to elicit something that could be generalized to other views, especially those concerned with the topic of the sources of normativity. Our definition of normative domains, insofar as these characterize a dimension of our practices, aims to clarify how normativity can be linked to agency in the context of such practices. A normative domain is a certain field of human agency defined by the sort of achievement that characterizes it. In this sense, knowledge, considered as an achievement, constitutes the domain that is called "epistemic". In order to infuse normativity, an achievement must involve more than mere success in performing a task or an activity; it requires taking into consideration how success is obtained. Success is a valuable outcome of our activities but, as we will argue, the contribution of an agent to the obtaining of this particular state is critically relevant to evaluate it as an achievement. What is constitutive of the normative status of knowledge is explained in terms of how an epistemic agent is engaged in the task of knowing. It is the sort of engagement that leads to success that ultimately explains the normativity of knowledge. To elucidate what we mean by engagement, the last section of our paper proposes to appeal to the idea of adopting an epistemic perspective.

We will proceed as follows. A first section will very briefly introduce the normative question in epistemology; the second section will place the issue within the framework of agent-centred epistemologies and will criticize a model that views engagement in terms of agents' motivation; the last section of the paper will develop the main tenets of what we will dub a constitutive model of epistemic normativity.

\section{Epistemic Normativity}

It is widely held that epistemology is a normative discipline. As such, it pertains to what in section 3.1 we will characterize as a normative domain, that is, a field of human practices that establishes a certain standard of success due to the competences of the subjects in these practices. Although some philosophers have thought that one of the main epistemological tasks was to provide guidance for our cognitive conduct, the normative character of epistemological reflection is not exhausted by this regulative task. Moreover, the regulative task does not stand on itself. On the contrary, a justification of how normative standards emerge is also needed. With this aim in view, we seek 
to understand which are the normative conditions associated with believing and knowing. As cognitive beings, we want our beliefs to be correct and to count as knowledge, and we take this to be good and worth pursuing.

Knowledge is the sort of thing we care about. Why is this? We consider it a good thing to possess knowledge and to strive for it. We also judge our cognitive activities in terms of how we think that beliefs should be formed in order to be justified, to be rational or to count as knowledge. It is not contentious that normative claims pervade our cognitive life and have real psychological and practical effects upon us.

It is significant that most recent epistemology has turned its focus of attention towards questions regarding epistemic value. Some authors have even ventured to talk about a "value turn" in epistemology (Riggs 2008). The so-called value problem has become a point of departure. The problem is easy to formulate: why is knowledge distinctively valuable? Or, better, why is knowledge valuable over true believing? (Pritchard 2007, p. 86). A certain value-driven epistemology has grown up around these questions; thus the discussion on epistemic normativity has mainly been couched in terms of value. No doubt epistemology has to be concerned with identifying the fundamental epistemic values. But this does not exhaust the normative problem as such.

A different possibility is to observe how a performance qualified as knowledge (Sosa 2011) reveals how the subject is committed to certain normative standards that constitute the valuable properties of the epistemic domain. Let us now briefly set forth which aspects of the normative problem we are interested in. Beliefs are subject to normative assessments. Talk of a belief as rational or as amounting to knowledge makes reference to the way the belief is in conformity with certain standards and meets certain requirements. Both standards and requirements determine the correctness of the belief. Correctness expresses normativity. And it does so because to take a belief as correct means to accept at once certain commitments in the regulation of belief. Naturally enough, the commitments that will matter are those that reflect the authority that standards and requirements exert on the believer. Specifically, to accept these commitments requires the believer to have some sensitivity to, even some feeling of being concerned with, the authority of the standards. So, when we talk about knowledge as valuable, we assess how the subject's commitment contributes to the success of the performance of 
so-called knowledge. And if our interest is the normativity constitutive of knowledge or the question of why knowledge is valuable, we should ask for the source of the authority of such demands.

Thus if one wants to address normative issues appropriately, one should take into account the expected responses of those subjects that are sensitive to the requirements and standards distinctive of the performance of a certain task. Take, for instance, a situation where the agent's action is praiseworthy and one is prone to acclaim with regard to what the agent has attained: "Well done!" The appropriateness of the assessment will depend on the fact that such agents are sensitive to the values that reflect the correctness of the task. That is, they should be concerned by those valuable properties. This sensitivity could be expressed either (a) implicitly through the systematic cognitive responses of the agent, or (b) explicitly through a series of commitments to what the agent thinks she ought to do or believe in the epistemic case.

In situations where agents exhibit this kind of sensitivity (in either of the two forms we have suggested), we can say that they adopt a normative stance. Such a stance consists of viewing and interpreting the situation as one where certain normative demands must be met in order to accomplish a particular task. In so doing, the requirements are taken to be authoritative over the subject. She will be prone to regulate her believings and disbelievings according to the requirements underlying the identification of those valuable properties that characterize the task. The adoption of a normative stance is a need for those beings that are able to be in charge of their lives and responsible for their deeds, no less in the cognitive realm.

Therefore, the normativity issue that we are interested in could be put in the following terms: one must explain how an agent is capable of placing herself in a certain normative (epistemic) stance.

Our point of departure is, then, the epistemic agent within an evaluative context, and the questions to be addressed are the following:

1. Which are the normative properties in force within an epistemic context?

2. In what sense can it be said that these are properties that exert authority over the epistemic agent?

Let us notice that by "normative property" we don't necessarily mean "moral property". Some authors have suggested that such questions should be considered within a broader theoretical context, that 
of moral normativity. So, for instance, Zagzebski has claimed that "knowledge is important because it is intimately connected to moral value and the wider values of a good life. It is very unlikely that epistemic value in any interesting sense is autonomous" (Zagzebski 2003a, p. 26). Nonetheless, it should be pointed out that there is an obvious risk in embracing this dependence of the epistemic on the ethical. It is true that the value turn can benefit from drawing analogies out of the ethical domain. Certainly, when one adopts a normative attitude of any kind, a sort of good is always involved, but this only means that knowing, in our case, is regarded as valuable and agents as praiseworthy or blameworthy insofar as they are concerned with the normative status of the beliefs they hold. But are we committed to the idea that all the goods are, in a sense, connected to moral values? Although the aim of this paper is not to argue directly for the autonomy of epistemic normativity, we will contend that normativity denotes a sort of authority and that this authority is rooted in the way epistemic agents tackle cognitive problems and succeed in solving them. The idea is that the properties that confer the status of "epistemic" are not, in any interesting sense, moral; it suffices, with respect to the normative issue we are dealing with, that they are "constitutive" properties of knowledge considered as an achievement. ${ }^{1}$

In the next section we shall examine how a version of the socalled agent-centred epistemologies deals with the normative question. Agent-centred epistemologies not only have the tools to address the value problem, they are also in a good position to confront the difficulties raised by the authority question, given the role the subject plays in the explanation of the normative status of knowledge.

\section{Agent-Centred Epistemologies and Motivation}

It is not surprising that the value problem has been of particular interest for reliabilist epistemologies, given the role that naturalist leanings play for their inspiration. Any view that regards knowledge

\footnotetext{
${ }^{1}$ Compare our approach with the quite close views that Pamela Hieronymi holds regarding the normativity of believing (Hieronymi 2008). She distinguishes between the reasons one might give for answering to the question of why someone believes that $p$ and the reasons of why to believe p. Believings, she adduces, can occur without reasons, but we are answerable for their content, even though such attitudes as believings are not voluntary. Analogously, we distinguish between the question of how worth is to know that $p$ (because $p$ is true), and the questions of how worth is to know that $\mathrm{p}$ (because knowing is an achievement due to the appropriate exercise of our competences).
} 
as true belief derived from a reliable process is confronted with two immediate problems: first, the view is too liberal unless it offers some hints regarding how to restrict the sort of reliable processes that are knowledge-conducive; second, reliability as such does not seem to add any value to a true belief; a reliable process is valuable because it is truth-conducive, its value is "swamped" by the value of the true beliefs it helps to obtain (Kvanvig 2003).

Agent-centred epistemologies offer possible answers to both problems. There is a way to rule out "processes that are strange or fleeting" (Greco 1999, p. 286) — to include among the knowledgeconducive processes only those that are stable features in the cognitive life of the subject and that shape her cognitive character. For Greco, this move also allows us to account for knowledge's being subjectively appropriate, so as to involve "sensitivity to the reliability of one's evidence" (Greco 1999, p. 289), and offers at the same time some hints regarding how to address the value problem.

Now the value of knowledge derives from an exercise of the cognitive traits of the subject. Thus agent-centred epistemologies seek to settle the value problem by appealing to an epistemic agent who grounds what is valuable or normatively significant in cognitive activities. Let us assume that the cognitive character of the agent is given by a set of intellectual virtues. Virtue epistemologies are, primarily, agent-centred epistemologies. Firstly, they offer a definition of knowledge as true belief out of intellectual virtue. Secondly, in virtue epistemology, the success relevant for epistemic assessment is the one that is due to the agent, due to the exercise of the virtues that form her cognitive character. Epistemically significant success is an achievement, that is, success attributable to the agent (Sosa 2003 and 2007) or something she deserves credit for (Rigss 2002, Zagzebski 2003a and 2003b; Greco 2003 and 2010).

Linda Zagzebski has defended a version of virtue epistemology that embraces a very thick conception of the virtues. Each virtue includes a motivational component along a reliability component. Knowledge arises, according to her, out of an act of intellectual virtue (Zagzebski 1996). ${ }^{2}$ So, motivation plays an important role in accounting for knowledge:

an act of intellectual virtue is an act motivated by the motivational component of intellectual virtues, is an act an intellectually virtuous

${ }^{2}$ More recently, she has introduced some modifications in her theory and she likes to express her view on knowledge in the following terms: "knowledge is an act of intellectual virtue" (Zagzebski 2003b, p. 153). 
person would characteristically do in these epistemic circumstances, and is successful in reaching the truth because of these other features of the act. (Zagzebski 2003b, p. 152)

Intellectual virtues may involve many different motives, but one of them is fundamental: the love of truth. The motive is a feature of the agent that makes believing more valuable in a way that is not open for the reliability component. And this is so because the motive as such has a sort of value that can be conferred on the acts of intellectual virtue that it motivates. "I propose that love of truth is a motive that confers value on acts of belief in addition to any other value such acts might have" (Zagzebski 2003b, p. 149). When we know that the act has been motivated by the love of truth and not by any other spurious motivation, we admire the act as better even if in both cases we have succeeded.

We are not interested here in criticizing Zagzebski's views on virtue and knowledge, but to outline a model that could account for the normativity of knowledge by appealing to the motives of the cognitive agent. ${ }^{3} \mathrm{We}$ will dub it motivationalism. The interest of motivationalism lies in two facts: first, it is easy to see how it could illuminate the distinctive value of knowledge; second, it gives a certain image of the agent's involvement in the acquisition of knowledge (through the acceptance of beliefs out of a well-motivated act of intellectual virtue). The emphasis is shifted on to agents, but just one aspect of virtuous agency is essential in accounting for what is distinctive of the epistemic status of knowledge, that is, the motive that guides the cognitive activity of the agent through her acts of virtue. This internal link between acts of virtue and motivation allows to distinguish between the deeds of the agent and mere events that happen to him.

Thus motivationalism accounts for epistemic normativity in the following way:

${ }^{3}$ Zagzebski's theory of epistemic normativity is complex and full of interesting remarks. For Zagzebski, knowledge as such is valuable and its value belongs to the admirable. There is also a strong connection between getting knowledge and getting credit for the truth; but the believer gets credit for the truth in an appropriate way by being motivated by the love of truth. Knowledge is something we care about and as such it plays a key role in our lives and in the obtaining of other valuable things, even in the shaping of our moral lives. As we have said, we do not intend to address Zagzebski's work and criticize her views. In the following, we sometimes take up ideas of hers in order to build and reject a possible model of epistemic normativity couched in terms of adequate motivations of an epistemic agent. 
(M) S's acts (believings) acquire an epistemically normative property (and thus they become acts he deserves credit for) if and only if they are successful (true believings) due to the fact that the agent acted (believed) moved by an appropriate (epistemic) motive.

For the agent to be creditable for her knowing state, the motivationalist claims, it matters how it has been attained, that is, how it has been motivated. There is a right way of attaining the epistemic good we ascribe to knowledge and this is the attaining of the good with the right motivation. This also explains the responsibility of the knower in the acquisition of valuable epistemic states. ${ }^{4}$ By referring to the virtuous acts of the agent as part of what defines knowledge, this view attempts both to solve the value problem and to account for the responsibility of the epistemic subject. We could say that by being subject to the "authority" of good motives, the agent becomes responsible for her epistemic deeds. Authority accrues from the motives to the believings. Moreover, the subject gets credit for her acts even if the acquired beliefs are false. It is enough that the intellectually virtuous person does what she would normally do in the circumstances, guided by the right motivation.

There is a straightforward objection to any view that takes motivation to be a constitutive feature of the normative status of knowledge. It is extremely easy to identify cases of knowledge where it is at least dubious that there are any motives involved. For Zagzebski, any virtuous act is characterized by reference to a motivational component, but this component is not to be found in ordinary perceptual or memory beliefs. Could such cases count as knowledge? So presented, the objection has some initial plausibility, but we cannot ignore the fact that it can be used against any agent-centred epistemology that assumes that perceptual and memorial processes are performed automatically, without any significant agential contribution. However, there is a possible general answer to these worries: the agential contribution is made visible when perception and memory become part of a web of commitments that form a background for the evaluation of our perceptual and memorial beliefs. In human knowledge, perception or memory perform virtuously when the outcomes become rationally sensitive to defeaters. Motivation could now enter the description of the process as a feature of our capacity to become

\footnotetext{
${ }^{4}$ Talk about motivation and responsibility raises a question about the voluntarieness of belief. This is a problem that needs to be addressed by any agent-centred epistemology. See below (section 3.2).
} 
sensitive to defeaters. Thus the love of truth also guides us in our acceptance of perceptual and memorial beliefs.

The crucial issue in motivationalism is whether the motivational component of the virtues plays any significant role in accounting for the normative status of knowledge. Let us assume for the moment that virtues involve motives; it would be undesirable to describe our cognitive life as lacking any emotional and motivational drives. And yet the question remains: in what sense do they contribute to constituting an epistemic normative status? The key claim in motivationalism is that motives really affect the act of believing in such a way as to render it somehow epistemically better.

But it is not difficult to see why this cannot be true. Motivation is not constitutive of achievements, at least in the cognitive domain. Let us draw an analogy with other kinds of performance where excellence and motivation could also be involved. Consider the case of a famous physician whose diagnostic capacity is greatly admired; let us suppose that he is even better in particularly challenging and difficult situations. Is it true that we would admire his performance as a physician because of the motivations that guide him in carrying out his tasks? Imagine a physician who is never concerned about whether his motivations have anything to do with care for his patients' wellbeing. Let's call him Dr. House. How is motivation supposed to enter into the assessment of his medical performance? Vary the motives and check whether the quality of the performance is affected in a significant way.

Case 1. Dr. House has an excellent record of performances in healing his patients, but he has never been moved by concern for their well-being.

Case 2. Dr. House is a very clumsy, but lucky performer, though he has always been moved by concern for their well-being.

Case 3. Dr. House is an adroit and safe performer, moved by the best motives with regard to the health of his patients.

A motivationalist is committed to the claim that case 3 shows how the value of the motives accrues to the value of the performance, that case 2 reveals how motivations are not sufficient to add value when they do not constitute an agential contribution to the excellence of the competence involved, and that case 1 does not challenge her position because she only considers cases where performance is really due to the motivation. But in this last case she must also offer an explanation as to why the performance is excellent. Or does it not 
make sense to speak of an excellent performance when this is not due to the motivation of the agent? If it does - she could claimit is because it is due to the reliability component of the virtues Dr. House exerts. And we have seen that reliability cannot account on its own for the value that accrues to the outcomes in addition to what makes them valuable in the first place.

So the motivationalist could reply that in case 3 , where the performance is due to the good motivations, this performance is of a new kind more valuable in virtue of the motives, and that is why it involves a new sort of excellence. Motives modify performance. As the set of examples shows, there is a sense in which performance is independent of motivation, but this fact does not say anything against the possibility that the performance itself has been modified by the motives. We cannot measure the value of the performance in terms of external outcomes. We risk being under the influence of the "machine-product model", as Zagzebski herself calls it. We cannot think of the outcome as external to the act; if we want to have a valid analogy with the cognitive realm, "the intended outcome is a property of the act itself" (Zagzebski 2003b, p. 151).

Now, in what sense do motives change Dr. House's good performance? Truly, in no significant sense with regard to the exercise of the competence of diagnosing and healing patients. This competence remains unaffected by whatever his motives are. And, as case 2 shows, in contrast with the other two cases, the performance is appropriate because of him; it is not just the result of healing people that makes the performance good; he is doing it in the right way, he is not being lucky. It is not true of him that he heals the patients because he desires their health, even if he does. It could even be true that he acquired such a competence of diagnosing and healing because he really cared about sick people; but this is contingent regarding the normative standards that are constitutive of a competence in diagnosing and healing.

Again, someone could object that epistemic competencies are different in this respect. Consider, for instance, an analogy with moral virtues. Acts motivated by compassion are better than mere acts that lead to relieving suffering. And truly enough, acts of compassion are good even if they don't actually achieve the aim of relieving suffering. Cognitively virtuous acts are alike; acts motivated by an aversion to falsehood are better than acts that merely aim at avoiding falsehoods for spurious motives. And again, it seems true that acts of virtuous believing motivated by an aversion to falsehood are good even if 
they don't avoid the false But, in virtue of what? We would say, in virtue of the modal connection between the use of a competence and the avoidance of false beliefs. Performances would deserve positive evaluations even in those worlds where the Cartesian evil genius is acting, insofar as they are controlled by a competence that would lead us away from falsity in a normal world. First, the situation would be the same when we are not motivated by the avoidance of falsehoods, insofar as the competence is well constituted as regards the aim of avoiding falsehoods. And second, the same does not seem to be true in respect of compassion.

This does not mean that there could be no situations where bad motivations might affect our truth-tracking competences. The motivationalist could reply that, in these cases, motivation is normatively relevant for the assessment of belief. But this is not the question at issue: what matters is whether motivation constitutes good truthtracking in such a way that only if I am rightly motivated by the love of truth my attainment of the truth is virtuous and counts as knowledge. There could be belief-forming processes that, even if they were to lead us to the truth, wouldn't do it in the right way. But is the appropriateness to be explained in terms of motives? Consider a case of wishful thinking. The subject does not seem to care about the truth; she cares just about what she wants to believe. It seems as if she believes because she so wants to believe. Imagine that she is right in her belief because there is evidence for the belief. Insofar as we cannot just believe like that, at will, there must be "some connection between the fact that there is good evidence for the belief and my belief" (Zagzebski 2003b, p. 151). But does she believe because of that good evidence? The force of Zagzebski's argument depends on viewing the first "because" as normative. "Not caring about the truth" regulates the belief in such a way that prevents the evidence from playing its epistemic role. That makes the second "because" a mere psychological one, without normative force. It is as if the roles had been reversed. The epistemic fault resides in not taking the evidence as evidence, that is, as normatively relevant in the formation of the belief. Motivationalists would have to claim that it is just by caring about the truth that we are able to take evidence as evidence. But caring about the truth is a mere psychological disposition that is not constitutive of the normatively relevant fact, which is the exercise of epistemic competencies that answer to evidence as evidence. The question is not whether I can take the evidence as evidence without caring about the truth; we are probably beings unable to do so. The question concerns which feature is playing a normative epistemic 
role in the regulation of belief. It is possible to conceive a case where someone obtains knowledge because she adequately responds to the evidence, but her motivational conditions regarding the truth of a particular belief are not appropriate.

A good motive is the psychological condition that reflects the subject's disposition to conform to certain normative standards. But the motive as such does not constitute either the normativity of the standards or their authority. It must be considered a symptom that could help to decide whether an agent is engaged in a certain task, but it does not determine correctness in performing it. So it is not accidental that in order to distinguish a good motive from a bad one, we first need to have some conception regarding which normative properties are constitutive of the domain in question. It is therefore not surprising that we use tautological expressions to describe a good performance by referring the right motives: the good performance of avoiding falsehoods is moved by the good motive of avoiding falsehoods. And the same happens with truth or knowledge as motives.

\section{A Constitutive Model of Epistemic Normativity}

Our argument so far has established the need to introduce considerations about the nature and place of the epistemic subject in order to account for the normativity that characterizes the epistemic domain. But we have also seen how the contribution of the subject cannot be just theorized in terms of her motivational involvement in cognitive tasks. The normative issue cannot be solved by insisting on agents' motives, mainly because although their psychological force could contribute to explaining why they behave in the way they do, this fact does not tell us anything about the correctness of their epistemic agency.

In this section we will sketch a model of epistemic normativity focused on the way a certain domain of activity is constituted as normatively stable. We are interested in identifying those features that become authoritative for the agents within the domain, and in explaining why they are normatively compelling. Our aim is to characterize what we will call a "normative domain" and apply the results to the "epistemic domain". We will first argue that a conception of knowledge as achievement is central to the constitution of the normative domain of epistemology; second, we will argue that an agent contributes to the constitution of the domain insofar as she becomes involved and engaged in certain tasks. The result will be a kind of agent-centred epistemology that accounts for epistemic normativity in 
terms of how the agent is engaged in the accomplishment of certain tasks.

\subsection{The Epistemic Normative Domain}

\subsubsection{Normative Domains}

Human activities are built around some acts, facts and, sometimes, artefacts that are proper to them. Driving, for instance, involves human behaviour, conventional facts and obviously some artefacts (roads, vehicles, signposts, etc.) that help organize the task in an appropriate manner. Or take horse races: many facts about horse behaviour or horse characteristics, together with jockeys' equestrian skills and the artefacts that make riding possible, characterize the domain of horse races. Entities within the domain are interestingly evaluated along many dimensions. Consider horses. They are assessed in terms of elegance, strength, or speed. But not all of the assessments are at the same level in the domain of horse racing. A plethora of possible assessments seem to converge towards a fundamental value: speed. This convergence makes it possible to identify a success condition that will characterize the activity.

We will call normative domains those fields of human activity that are defined by their own sort of achievement. Regarding the overall field of human agency, only one type of success can be regarded as constitutive of a normative domain, and this is the success due to some accomplishment on the part of the agents when they carry out the tasks proper to the domain. Success due to the work of the agents is usually considered an achievement. Thus normative domains are built around their corresponding achievements. These become goals pursued by the agents and in reference to which the activities of the domain are ordered..$^{5}$ For the agent to regard it as an achievement, the aim must be reached in virtue of the natural or social endowments, the faculties or the agential conditions of those who pursue them. If an achievement has become a goal worthy of being pursued it is because we have shifted our natural dispositions to put the blame or praise for our deeds on the qualities of the agents. This shift means that we honour certain acts that lead to success without the intervention of luck in terms of the contribution

${ }^{5}$ The normativity of the domain is always conditional, that is, it depends on the decisions of the agents to play the "game". For instance, if you choose to play chess, you should attempt to win due to the best use of your faculties. We take games to be paradigmatic examples of normative domains. 
made by the appropriate dispositions and engagement of the agents. Within the domain, success is valuable, but it does not constitute the normative domain as such. Lucky success is valuable, but it is far from contributing to explain how a domain of activity can become normatively stable and compelling for the agents.

In our view, it is the way the agents are involved in the attainment of success that helps to explain how a domain is constituted as normative. Agents need to contribute to the obtaining of valuable goals through the use of their faculties, skills and competencies. Moreover, many normative domains, once constituted, are subject to sanctions and quality controls. Most of them are even socially instituted in order to set standards as regards the abilities and responsibilities of agents. Activities like driving, teaching, health care, etc., are good examples of socially regulated normative domains. It is important to note that drivers, teachers, or physicians are not assessed for what their motivations are supposed to be, but for their competencies and their willingness to assume their respective professional responsibilities. In other terms, they are evaluated for their capacities to reach the goals proper to their domain of competence; they are assessed for their achievements.

\subsubsection{The Epistemic Domain}

Cognitive activity also constitutes a normative domain in virtue of the sort of achievement that is proper to it. There is a domain of epistemological significance wherever the achievement that we identify with knowledge matters, as opposed to mere success (true belief). As a normative property, "knowledge" names a human attainment. It is success due to the work of agents, just as in any other normative domain. At some stage of their cognitive development, human beings start to undertake activities and practices oriented towards the obtaining of knowledge. Here too the agential conditions (faculties, competencies) must contribute to the attainment of the aim. Again, agents will now become the primary objects of assessment, of praise and blame, and their assessment will have to do with the way they are involved in achieving success within the domain. The credit we attribute for believing truly is accounted for in terms of the contribution made by the dispositions and the appropriate engagement of the agent in the attainment of success. Lucky true beliefs do not suffice to constitute a normative domain of epistemic significance.

One can imagine a stage in the cultural development of a community where knowledge in our sense was less valuable than, for 
example, perseverance in a tradition, the acceptance of social inherited testimonies or even oracles. But the important thing is that at some point of a possible cultural trajectory truth becomes valuable because it is obtained due to the contribution of reliable cognitive skills of the agents. It can be claimed that an epistemically normative domain is fully constituted when such a stage is reached, that is, once putative agents are assessed in such practices according to their competencies to reach the goals. At some moment during the process, and as a result of the stability and acceptance of such evaluative habits, agents become engaged in normative tasks. They may even become fully aware of their involvement in a normative practice. This realization is at the core of the conception they have of themselves as epistemic agents. As far as they act autonomously, they take a responsible attitude towards their own engagement.

Thus epistemology became a "domain of normative criticism" (Sosa 2007, p. 77), or a "critical domain" (Sosa 2007, p. 73) in virtue of two main features: a) human beings prove themselves skilful enough to attain the aim of knowledge; b) the world is benevolent enough to allow for such attainments. Thus knowledge became a normative achievement due to the convergence of certain factors that made it the fundamental value of the domain just when the agents' contribution was in place.

In our conception, the main tenets regarding the epistemic normative domain follow the lines of Sosa's epistemology. In his recent book, A Virtue Epistemology. Apt Belief and Reflective Knowledge, he suggests that epistemic virtues and competencies are constitutive of the attainment of fundamental value (Sosa 2007, p. 88). Our idea is that solving the normative question in epistemology involves adding some further considerations regarding the way agents intervene in the acquisition of knowledge. The very constitution of the epistemic domain will depend on the way the subject can be engaged in an epistemic task, so that success is attained in virtue of that engagement.

The following three features would summarize the constitutive characteristics of the epistemic domain:

1) Both truth and how truth is attained are valuable within the domain due to the contribution of the agents. In a sense, truth remains the fundamental value in epistemology, but only to the extent that it is qualified as "deserved" truth, that is, truth attained due to a virtuous competence. 
2) Epistemic virtues, understood as stable and reliable dispositions, are crucial facts in the constitution of an epistemic normative domain. They are the qualities for which the agent is primarily praised and blamed.

3) To attain the truth due to the subject's competencies (or virtues) is the constitutive fact of the epistemic domain. Beliefs thus acquire the property called aptness. A belief is apt when it is true because competent (Sosa 2007, p. 23). ${ }^{6}$

To sum up, the "epistemological game" is constituted as a normative domain when truth is considered a valuable prize for those agents who virtuously win it. There are other ways to attain truth, but their epistemological interest is limited. They do not contribute to creating a space where normative properties constrain the work of agents.

\subsection{Epistemically Normative Engagement}

As we have seen, agent-centred epistemologies in the virtue-theoretic tradition explain the normative status of knowledge in terms of the kind of success that is reached through virtue, that is, through the competent exercise of skills and abilities (Greco 1999 and 2010; Sosa 2007). Such competencies must be "seated in the agent" (Sosa 2007, p. 86), but there could be many different models of what it could be for a competence to be seated in the agent. In any case, the basic claim is that a true belief would amount to knowledge because it arises out of the exercise of an agent's competence. She should be genuinely involved in getting the knowledge. What is at issue is precisely to what extent the agent is involved in the appropriate exercise of her abilities. True enough, for this involvement to be effective, it would be too demanding to always require an explicit reflective attitude towards the cognitive conditions (including the belief-states, the abilities at her disposal and the circumstances) she is placed in.

\footnotetext{
${ }^{6}$ On this view, aptness gets priority over safety insofar as what matters is to account for the constitution of the epistemic domain and not just to identify epistemic values. Even though safety (one of the strongest and most robust links between belief and facts) is among the most valuable and motivating goals in epistemology, it does not constitute by itself the epistemic normative domain. From a normative point of view, it cannot yet be considered as a fundamentally valuable goal, because mere safety does not guarantee knowledge to be a human achievement due to the exercise of epistemic capacities. Only aptness can be a robust guarantee for this.
} 
So, we shall distinguish between the mere agent's involvement because she exerts her cognitive abilities reliably leading to knowledge, and a complete engagement in the epistemic objectives, where such a task demands the ability to calibrate the adequacy of the particular constraints the epistemic scene presents. ${ }^{7}$

\section{a) Epistemic Agents}

Our constitutive account concedes a very significant place to agents in the normative structure of a domain. Thus our model must be completed with some remarks about the constitution of an epistemic agent.

Talk about epistemic agents is not without problems. It immediately suggests some commitment to voluntary and freely chosen acts of believing in analogy to intentional action. And it is generally agreed that human beings are not epistemic agents that could choose the beliefs they entertain in the very same sense in which they can intentionally decide to act. Nevertheless, it still makes sense to say that we are active (and not merely passive) in our believings and disbelievings. Our activity in the cognitive realm is exhibited in the way we exercise certain virtues and abilities in the control of our beliefs. We are actively engaged as long as we display, through the use of our faculties and virtues, some sensitivity to the standards that govern belief acquisition processes. If this is so, we need then to identify the conditions under which the agent could be said to be adequately sensitive to such standards.

In general, the agent displays this sensitivity insofar as she exerts a control over the outcomes that result from the use of her faculties. ${ }^{8}$ We need to say something with respect to how the competencies work to control the outcomes. There is a sense in which we could say that each faculty delivers some truths working in isolation from other faculties. But agential control requires something else. A first idea that must be considered is that we cannot conceive an agent as

${ }^{7}$ The question about what the epistemic involvement of agents consists in exceeds the aims of this paper. It could be claimed that it reflects at least the default epistemic work of the agent, that is, the exercising of her competencies in normal circumstances such that the competencies make a salient causal contribution to the success. In a sense, the agent obtains a degree of epistemic success that could be called normative without intervening as a fully engaged normative being in the task.

${ }^{8}$ Pamela Hieronymi has developed interesting ideas about the kind of control we can exert in our doxastic life. Being active regarding our beliefs does not amount to controlling a certain state of affairs as the outcome of our acts. We control some of our thoughts, in general, by thinking them. See Hieronymi 2006, and 2008. 
a mere bunch of (reliable) faculties. Virtue epistemology views the virtues as features of a person, meaning that it is the whole subject who will be assessed as the "author" of the belief.

This points to a second idea, one that is central to our consideration of what is needed to become a full epistemic agent. The good working of an epistemically virtuous agent must be viewed in terms of the cognitive integration she is capable of. The agent whose contribution is constitutive of the normative achievement of knowledge must be conceived as a cognitively well-integrated subject. This requisite has two different dimensions: one concerns the identification of the cognitive architecture that is necessary to talk of integration in the system; it is not implausible to think that the integration will depend on the acquisition of capacities of metacognition, that is, the capacities to evaluate one's own cognitive performance. Metacognition is a psychological competence whose function is to monitor and control the cognitive status of the system (Koriat 2000). As a psychological device, metacognition can be considered a necessary component of the architecture of a well integrated agent, although it would scarcely be sufficient since such integration also requires the actual working of the different capacities to satisfy a certain degree of coherence between their products. In this regard, the other dimension makes reference to the harmony with which the cognitive system needs to work in order for beliefs to attain the status of knowledge (Breyer and Greco 2008). There must be some monitoring mechanisms in place that help to identify conflicts in the information delivered by the different sources. This requirement of "cognitive integration" is an essential factor in the agent's engagement in cognitive tasks. The integration requirement argues for a consideration of the level of the agent as the proper level of epistemic assessment, rather than the variable performance of the different competencies. The reason is that such deliverances, although essential in the explanation of why an agent achieves knowledge, are not as such sufficient, because they are mainly considered in a piecemeal way. Compare, for instance, the attribution of health to the overall functioning of the organism rather than to the proper working of a particular organ.

Our conception of epistemic agents involves a third idea. A requisite of autonomy derives from certain constraints regarding how the subject is engaged in an epistemic task. Again, talk of autonomy within the cognitive realm can be regarded with suspicion. Is not autonomy a capacity for self-determination and self-legislation? And does it make sense, for instance, to talk about a doxastic legislator 
governed by an epistemic rational will? So, in what sense does engagement require autonomy? Consider the following. To be a full epistemic agent seems to require the subject to be able to attend to the circumstances under which she would be disposed to accept a true belief and eventually realize that she herself is involved in this kind of circumstances. In addition, the subject must be able to calibrate the adequacy of her faculties and abilities, that is, she must be in a position to assess to what extent her faculties are appropriate for the epistemic task she is engaged in. She will be in control of the epistemic task so long as she regards the abilities she is disposed to exercise as her abilities, and the circumstances as those where her abilities presumably would attain their cognitive goals. In this task, a mere exercise of a metacompetence, as Sosa (2011) proposes, perhaps is not sufficient to reach the level of full agency required for attaining a full level of knowledge. A knower performs as a unified subject when she is able to evaluate her own responsibility in the process of knowing. In this situation, the agent adopts a belief such that, when successful, it could be said that the achievement - knowledge - is attributable to her abilities.

This leads us to a version of the autonomy condition that is congenial to virtue epistemology. An epistemic agent acts autonomously insofar as she manifests her character in the "acts" of believing or disbelieving certain propositions. In order to do that, the agent must be able to take herself as a knower that weights her own abilities in each epistemic situation she is engaged in. Then the agent is so displaying a certain sensitivity to herself as a knower, that is, she is answering to the demands of the situation as essentially epistemic and normatively compelling. A full epistemic agent is a cognitive being such that she "acts" by the conception she has of her own epistemic condition. That does not answer to a requisite of self-determination as self-legislation, but it is in conformity with the other Kantian ideal of autonomy: a capacity for thinking for oneself. Now an autonomous epistemic subject is one endowed with a set of capacities that allow her to take herself as the owner and as the assessor of these beliefs. She views herself as the source of those beliefs that are epistemically grounded on the adequate exercise of her own competencies. ${ }^{9}$

${ }^{9}$ In a recent paper, Fischer and Tognazzini (2011) distinguish between two aspects of the claims of responsibility: attributability, that talks "about the connection the agent has with her action", and accountability, that talks "about the potential interaction the agent might have with her moral community" (p. 381). We analogously distinguish between the same aspects regarding epistemic appraisal. The normative stance we are defending here has to do with the first aspect of attributability to the 
Thus, once we have cleared up what we understand by normative domains and by engagement, we are now in a position to introduce a schema that would summarise the view on epistemic normativity that we propose as alternative to motivationalism.

(C) S's acts (believings) acquire an epistemically normative property (and thus they become acts she deserves credit for) if and only if they are successful (true believings) due to the fact that the agent acted (believed) by virtue of her engagement in an appropriately constituted domain.

It is not the fact that the virtues are constituted by intrinsically valuable motivations that explains why epistemic achievements are valuable, but the fact that an agent is appropriately engaged in tasks whose aim is to achieve the acquisition of knowledge.

\section{b) Engagement and Epistemic Perspective}

There is a sufficient condition for a subject to attain the level of epistemic agency. We propose to consider such a condition that of being able to take an epistemic perspective towards oneself. In our view, one takes an epistemic perspective when one considers oneself to be confronted with a particular cognitive problem such that one could be in a position to justifiably claim "I know that $p$ ". This is the way we consider that the agent is taking a reflective stance on her own possibilities for knowing in a particular scenario. Such a reflective turn is equivalent to a situation in which the agent is able to place herself in the particular circumstances of knowing and then to calibrate how favourable such circumstances might be in order to attain the goal of knowledge.

A brief sketch of what we mean by the idea that to take an epistemic perspective is sufficient for considering a subject an integrated and autonomous agent could be the following:

1. To take an epistemic perspective is something that involves an unavoidably singular point of view, that is, a singular firstpersonal point of view in a particular situation.

2. By taking such a perspective, the agent makes herself present as an agent in the epistemic scene with her peculiar first-person authority.

agent. But other concerns can be identified regarding the claims that a community of knowers could make on the epistemic agent. We thank an anonymous referee for an objection in this sense. 
3. Taking a perspective on one's own cognitive possibilities implies that the agent is in fact sensitive to the epistemic conditions in which she finds herself.

4. As a consequence of this sensitivity, she is able to see the situation in the light of the epistemic, normative properties that are in force within the domain. ${ }^{10}$

In order to support our claim that an epistemic perspective is a sufficient condition of epistemic engagement in a normative task, we suggest an analogy between taking a perspective and the attentional process. Consider the following examples:

A first analogy links driving and attending. Thus, let us suppose that someone is driving correctly. Very often, she is not required to attend specifically to the road conditions. Nonetheless, at certain moments, the subject says to herself: "Hey! Pay attention to what you are doing!" Putatively, this recognition involves an evaluation of the road conditions, an additional evaluation of her own capacities to cope with the situation, and finally, a conscious involvement in the situation. When these conditions are met, it can be said that this driver is concerned by the normative claims involved in apt driving and that she views the situation under the conditions of a normative engagement in it.

A second analogy helps us to highlight this point. Consider for instance the case of a painter: when she takes a perspective on her painting, we can consider that she is mainly attending to the relevant aesthetic properties of her work. The agent then takes part in a normative domain by ensuring that her work is constrained by these properties she attends to. In neither of these examples is the situation over-intellectualized in any significant sense. Firstly, because only in a few cases does the subject need to put into play a complex mechanism of explicit recognition and reflective guidance of her behaviour. Secondly, because this recognitional capacity works, in our model, in analogy with the attentional processes. ${ }^{11}$

Our idea is that both the process of paying attention and taking a perspective share certain relevant features:

\footnotetext{
${ }^{10}$ Our notion of adopting an epistemic perspective qualifies Sosa's perspectivism. Our view emphasizes above all the active presence of the subject through the normative engagement in an epistemic task.

${ }^{11} \mathrm{We}$ are not contending that in every case of acquisition of knowledge the subject must reach such a demanding level of epistemic self-consciousness. But it is at least required — this is our proposal — when the agent's responsibility for knowledge is at stake.
} 
1. Both are transparent in the sense that one is attending to the thing itself and not to an internal representation. Thus, attention focuses on the objective features of a scene under a public description. Analogously, perspective focuses on the objective circumstances of knowing, and not just on the internal states of the subject.

2. Both are essentially perspectival: they depend on the point of view of the "observer".

3. Both have internal as well as external success conditions. Attending, analogously to taking a perspective, makes you aware of these conditions. Attention can be fragile either because of internal working deficiencies or because of environmental circumstances.

Thus, when one adopts an epistemic perspective, as when one attends to something, it can be said that the agent is made present in the cognitive scene as a cognitive agent. One cannot notice what is happening without knowing oneself to be concerned by the normative claims in force within the epistemic domain. In this regard, our conception of epistemic normativity requires that the subject exhibits a certain sensitivity to the correctness of her own epistemic standing when performing a task, and it takes some distance from a conception of normativity in terms of mere performance, as seems to be Sosa's view. When taking an epistemic perspective, the agent is attending to the epistemic claims of the situation (and not to other kinds of claims as for instance aesthetic, or ethical ones, even though they could be relevant to the situation). By doing this, the agents are viewing the situation as one in which they need to engage normatively in order to achieve the task successfully. ${ }^{12}$ And this, and no more, shows an explicit engagement in the particular cognitive situation.

An agent engaged in an epistemic task is an agent capable of adopting an epistemically normative stance. When the agent is engaged in the epistemic task, she is identifying, at least in an implicit way, those features of the situation that are normatively compelling. So by becoming an engaged agent, she is in position to respond to the

\footnotetext{
${ }^{12} \mathrm{We}$ are here supposing that the adoption of a normative stance is something that is made within the overall cognitive working of an epistemically virtuous agent who reliably reaches true beliefs. Otherwise, we would be liable to the obvious objection that the agent could think herself to be in a good epistemic position while she is not. On the contrary, we take the virtuous agent as someone who could also virtuously adopt a normative stance on her epistemic engagement.
} 
normative properties that are constitutive of the epistemic domain. To accomplish the task can now be seen as the result of meeting the normative demands of the situation. We have understood engagement in terms of how the epistemic subject is attending to the success conditions of the task. By engaging in a normative task, the agent is viewing it as a task where success is reachable because of her contribution. Success is "in her hands". In a sense, only beings capable of acting by the conception they have of themselves could be normatively engaged in this way. Therefore, we can consider that epistemic agents are just a subset of cognitive beings that act in virtue of their attention to the normative demands that are characteristic of a certain kind of achievement.

\section{Conclusion}

An issue that has acquired a certain prevalence within the virtuetheoretic tradition is the possibility of attributing responsibility to epistemic agents. Motivationalism, for instance, has been defended as a specific form of responsibilism because it seeks to explain how we are responsible for the knowledge we acquire in terms of the right motives of the epistemic subjects. This is a far-reaching issue that we cannot address here. It will suffice to indicate that our model allows for an attribution of responsibility for knowing to an epistemic subject. We explain this notion of responsibility as attributability by referring to the epistemic engagement of the agent. But this does not settle whether we are allowed to take other subjects to be morally liable to our epistemic demands; that is an issue primarily relevant for an ethics of belief and is not part of an explanation of the constitutive nature of knowledge.

To sum up: we have shown that the normativity of knowledge rests on the contribution of the epistemic agent to the fulfilment of certain tasks. Such a contribution is epistemically significant when the aptness of beliefs is due to the exercise of the agent's cognitive faculties and the agent is able to take a perspective on the aptness of her own beliefs and the circumstances of knowing. In this way she becomes engaged in an epistemic task. Motivations are not here regarded as constitutive of the epistemic normativity, although they could play some role in the psychological states of the agent. Our constitutive view, therefore, takes into account both the objective process of attaining knowledge (understood as true belief due to the agent's competencies) as well as the subjective engagement of the agent in a normatively constrained task. Obviously, our brief remarks 
about the conditions necessary to become a full epistemic agent, conditions of cognitive integration and epistemic autonomy, need to be supplemented if we want to provide a full defence of our model on epistemic normativity. ${ }^{13}$

\section{REFERENCES}

Breyer, D. and J. Greco, 2008, "Cognitive Integration and the Ownership of Belief: Response to Bernecker", Philosophy and Phenomenological Research, vol. 76, no. 1, pp. 173-184.

De Paul, M. and L. Zagzebski (eds.), 2003, Intellectual Virtue. Perspectives from Ethics and Epistemology, Oxford University Press, Oxford.

Fairweather, A., 2001, "Epistemic Motivation", in Fairweather and Zagzebski 2001 , pp. 63-81.

Fairweather, A. and L. Zagzebski (eds.), 2001, Virtue Epistemology. Essays on Epistemic Virtue and Responsibility, Oxford University Press, Oxford.

Feldman, R., 2000, "The Ethics of Belief", Philosophy and Phenomenological Research, vol. 63, no. 3, pp. 667-695.

Fischer, J.M. and N.A. Tognazzini, 2011, "The Physiognomy of Responsibility", Philosophy and Phenomenological Research, vol. 82, no. 2, pp. 381-417.

Greco, J., 2010, Achieving Knowledge. A Virtue-Theoretic Account of Epistemic Normativity, Cambridge University Press, Cambridge.

- 2003, "Knowledge as Credit for True Belief", in De Paul and Zagzebski 2003, pp. 111-134.

— , 1999, “Agent Reliabilism”, in J. Tomberlin (ed.), Philosophical Perspectives 13. Epistemology, Ridgeview Press, Atascadero, pp. 273296.

Hieronymi, P., 2008, "Responsibility for Believing", Synthese, vol. 161, no. 3, pp. 357-373.

— 2006, "Controlling Attitudes", Pacific Philosophical Quarterly, vol. 87, no. 1, pp. 45-74.

\footnotetext{
${ }^{13}$ Versions of this paper have been read at a conference on The Value of Knowledge held in Amsterdam (August 2007), a conference on Epistemic Agency in Geneva (April 2008), and the workshop Normativity of Belief and Epistemic Agency (UNAM, Mexico, 2009). This research has been funded by two research grants from the Spanish Ministry of Science and Education (FFI2009-09049: Identity, Memory and Experience; and FFI2010-12054: Epistemology of Artifacts). We would like to thank Ernest Sosa, Carlos Thiebaut, Javier Gil, and participants in the workshops mentioned for having discussed the ideas in this paper with us and having helped us improve the text. We also thank two anonymous referees for their valuable comments.
} 
Koriat, A., 2000, "The Feeling of Knowing: Some Metatheoretical Implications for Consciousness and Control", Consciousness and Cognition, vol. 9, pp. 149-171.

Kvanvig, J., 2003, The Value of Knowledge and the Pursuit of Understanding, Cambridge University Press, Cambridge.

Pritchard, D., 2007, "Recent Work on Epistemic Value", American Philosophical Quarterly, vol. 44, pp. 85-110.

Riggs, W., 2008, "The Value Turn in Epistemology", in V.F. Hendricks and D. Pritchard (eds.), New Waves in Epistemology, Palgrave Macmillan, New York, pp. 300-323.

—_ 2002, "Reliability and the Value of Knowledge", Philosophy and Phenomenological Research, vol. 64, no. 1, pp. 79-96.

Sosa, E., 2011, Knowing Full Well, Princeton University Press, Princeton/Oxford.

- 2009a, Reflective Knowledge. Vol. 2. Apt Belief and Reflective Knowledge, Oxford University Press, Oxford.

- 2009b, "Replies to Commentators on A Virtue Epistemology", Philosophical Studies, vol. 155, pp. 137-147.

— 2009c, "Knowing Full Well: the Normativity of Beliefs as Performances", Philosophical Studies, vol. 142, pp. 5-15.

— - 2007, A Virtue Epistemology, Oxford University Press, Oxford.

_ 2003, "The Place of Truth in Epistemology", in De Paul and Zagzebski 2003, pp. 155-179.

- 2001, "For the Love of Truth?", in Fairweather and Zagzebski 2001, pp. 49-62.

Zagzebski, L., 2003a, "The Search of the Source of Epistemic Good", Metaphilosophy, vol. 34, nos. 1-2, pp. 12-28.

— 2003b, "Intellectual Motivation and the Good of Truth", in De Paul and Zagzebski 2003, pp. 135-154.

- 2000, "From Reliabilism to Virtue Epistemology", in G. Axtell (ed.), Knowledge, Belief and Character, Rowman and Littlefield, Lanham, pp. 113-122.

— 1996, Virtues of the Mind: An Inquiry into the Nature of Virtue and the Ethical Foundations of Knowledge, Cambridge University Press, Cambridge.

Received: July 7, 2010; revised: June 9, 2011; accepted: June 24, 2011. 